\title{
PEMBENTUKAN KP - ASI (KELOMPOK PENDUKUNG ASI) DALAM MEWUJUDKAN KADARSIE (KELUARGA SADAR ASI EKSKLUSIF) DI WILAYAH KERJA PUSKESMAS MEUREBO KABUPATEN ACEH BARAT
}

\author{
Fitriani $^{1}$, Veni Nella Syahputri ${ }^{2}$ \\ Fakultas Kesehatan Masyarakat Universitas Teuku Umar \\ fitriani@utu.ac.id
}

\begin{abstract}
ABSTRAK
Modal dasar pembentukan manusia berkualitas dimulai sejak janin dalam kandungan dengan memberi nutrisi pada ibu hamil dilanjutkan pemberian ASI ekslusif setelah bayi dilahirkan yaitu memberikan ASI saja termasuk kolostrum tanpa memberikan makanan serta minuman tambahan kepada bayi sejak dilahirkan sampai usia 6 bulan kecuali obat. Pemberian ASI sangat penting untuk tumbuh kembang bayi secara optimal, baik secara fisik maupun mental serta kecerdasan, oleh karena itu pemberian ASI perlu mendapat perhatian para ibu dan tenaga kesehatan agar proses menyusui dapat terlaksana dengan benar. (Proverawati, 2009). Kabupaten Aceh Barat merupakan salah satu Kabupaten Di Provinsi Aceh, dengan cakupan pemberian ASI Ekslusif belum mencapai Standar Pelayanan Minimal (SPM).Wilayah Kerja Dinas Kesehatan Kabupaten Aceh Barat terdiri dari 13 Puskesmas. Puskesmas Meurebo merupakan salah satu puskesmas dengan cakupan terendah yaitu 17,2 \% pada tahun 2016 . (Provil Dinkes Aceh Barat 2017).Hasil wawancara dengan penaggung jawab program Kesehatan Ibu dan Anak (KIA) di Puskesmas Meurebo menunjukkan informasi bahwa Puskesmas sudah menjalankan program dalam upaya meningkatkan pemberian ASI eksklusif yaitu berupa penyuluhan dan kelas ibu hamilk. Tetapi program ini tidak berjalan dengan baik karena tidak dilakukan secara berkesinambungan dengan alasan keterbatasan tenaga pelaksana dilapangan.Disamping itu belum adanya Kelompok Pendukung ASI (KP-ASI) di wilayah tersebut, memberikan kontribusi negatif terhadap cakupan pemberian ASI eksklusif.Melihatpotensidankondisiibuhamil serta meyusui diwilayah kerja puskesmas Meurebo, sangat penting dibentuk suatu programyang bertujuan untukmeningkatkan pengetahuanibuhamildanmeningkatkan kepatuhan ibu menyusui dalam dalam mewujudkan keluarga sadar ASI eksklusif melalui pendekatan peer group yaitu pembentukan Kelompok Pendukung ASI (KP-ASI).Anggota Kelompok Pendukung ASI dapat direkrut dari kader yang aktif dan ibu berhasil memberikan ASI eksklusif pada bayinya.
\end{abstract}

Kata Kunci: Kelompok, Pendukung, Air,Susu, Ibu, Eksklusif, Keluarga

\section{ABSTRACT}

The authorized capital for the formation of quality human beings starts from the fetus in the womb by nourishing pregnant women followed by exclusive breastfeeding after the baby is born, ie giving breast milk only including colostrum without providing additional food and drinks to the baby from birth to 6 months except medicine. Giving breast milk is very important for optimal growth and development of the baby, both physically and mentally as well as intelligence, therefore breastfeeding needs to get the attention of mothers and health workers so that the breastfeeding process can be carried out correctly. (Proverawati, 2009). West Aceh District is one of the Districts in Aceh Province, with coverage of Exclusive Breastfeeding not yet achieving Minimum Service Standards (SPM). The Working Area of the West Aceh District Health Office consists of 13 Puskesmas. Meurebo Health Center is one of 
the lowest coverage health centers, which is 17.2\% in 2016. (Profil of the West Aceh Health Office 2017). The results of interviews with the responsibility of the Maternal and Child Health (KIA) program in Meurebo Health Center show information that the Puskesmas has efforts to increase exclusive breastfeeding in the form of counseling and classes for pregnant women. But this program did not go well because it was not carried out on an ongoing basis due to the limitations of the field staff. Besides that, the absence of ASI Support Groups (KP$A S I)$ in the region, contributed negatively to the scope of exclusive breastfeeding. Looking at the potential and condition of pregnant and breastfeeding women in the work area of the Meurebo health center, a program which aims to increase the knowledge of pregnant women and increase adherence to breastfeeding mothers in creating a conscious family of exclusive breastfeeding through a peer group approach is the establishment of ASI Support Groups. . Members of the ASI Support Group can be recruited from active cadres and mothers successfully give exclusive breastfeeding to their babies.

Keywords: Group, Supporting, Water, Milk, Mother, Exclusive, Family

\section{PENDAHULUAN}

Modal dasar pembentukan manusia berkualitas dimulai sejak janin dalam kandungan dengan memberi nutrisi pada ibu hamil dilanjutkan pemberian ASI ekslusif setelah bayi dilahirkan yaitu memberikan ASI saja termasuk kolostrum tanpa memberikan makanan serta minuman tambahan kepada bayi sejak dilahirkan sampai usia 6 bulan kecuali obat. Pemberian ASI sangat penting untuk tumbuh kembang bayi secara optimal, baik secara fisik maupun mental serta kecerdasan, oleh karena itu pemberian ASI perlu mendapat perhatian para ibu dan tenaga kesehatan agar proses menyusui dapat terlaksana dengan benar (Proverawati, 2009).

Indonesia menargetkan $80 \quad \%$ ibu menyusui memberikan ASI ekslusif selama 6 bulan kehidupan bayi dan diteruskan pemberian ASI bersama makanan pendamping ASI (MP-ASI) sampai anak berumur 2tahun. Berdasarkan data Riskesdas cakupan pemberian ASI ekslusif pada tahun 2013 adalah 30,2 \%. Keberhasilan program pemberian ASI ekslusif tidak hanya tergantung pada ibu menyusui saja tetapi perlu dilaksanakan secara lintas sektor secara terpadu, disamping itu diperlukan peran serta masyarakat.Dukungan dari berbagai pihak sangat diperlukan diantaranya pihak manajemen, lingkungan kerja, organisasi profesi termasuk Ikatan Bidan Indonesia (IBI), dukungan politis, serta pemberdayaan wanita.(Depkes RI, 2012)

Kelompok Pendukung ASI merupakan salah satu kelompok pemberdayaan wanita. terdiri dari ibu hamil dan atau ibu menyusui dan kader kesehatan.yang bertemu secara rutin 2 (dua) minggu sekali atau setidaknya sebulan sekali termasuk kunjungan rumah pada ibu baru melahirkan untuk saling bertukar pengalaman, berdiskusi dan saling memberikan dukungan terkait kesehatan ibu dan anak khususnya seputar kehamilan, menyusui dan gizi yang dipandu/difasilitasi oleh motivator yang telah dilatih. 
Keputusan Menteri Kesehatan No.450/ Menkes/ SK/ V/ 2004 Tentang Pemberian ASI Eksklusif di Indonesia menetapkan pembentukan KP-ASI merupakan bagian dari Sepuluh Langkah Menuju Keberhasilan Menyusui (LMKM).

KP-ASI merupakan konselor teman sebaya, dimana konselor tersebut memiliki minat untuk berbagi pengalaman, ide dan informasi seputar menyusui dan hal-hal yang menjadi pendukung dan penghambat serta permasalahan selama menyusui. Sehingga dengan adanya kelompok ini dapat meningkatkan pengetahuan ibu dalam mewujudkan keluarga sadar ASI eksklusif.

Berdasarkan Laporan survai Pemantauan Status Gizi (PSG) Provinsi Aceh tahun 2017 menunjukkan proporsi bayi yang mendapatkan ASI Ekslusif sebesar 23,0\%, keadaan ini jika dibandingkan dengan hasil PSG tahun 2016 (23,5\%), terjadi penurunan, sebesar $0,5 \%$. Jika dilihat berdasarkan sebaran kabupaten kota, secara keseluruhan pemberian ASI eksklusif belum mencapai target. Rinciannnya terlihat pada grafik berikut (Poltekes Kemenkes Aceh, 2017).

Kabupaten Aceh Barat merupakan salah satu Kabupaten Di Provinsi Aceh, dengan cakupan pemberian ASI Ekslusif belum mencapai Standar Pelayanan Minimal (SPM).Wilayah Kerja Dinas Kesehatan Kabupaten Aceh Barat terdiri dari 13 Puskesmas. Puskesmas Meurebo merupakan salah satu puskesmas dengan cakupan terendah yaitu 17, 2 \% pada tahun 2016 (Provil Dinkes Aceh Barat 2017)

Hasil wawancara dengan penaggung jawab program Kesehatan Ibu dan Anak (KIA) di Puskesmas Meurebo menunjukkan informasi bahwa Puskesmas sudah menjalankan program dalam upaya meningkatkan pemberian ASI eksklusif yaitu berupa penyuluhan dan kelas ibu hamilk. Tetapi program ini tidak berjalan dengan baik karena tidak dilakukan secara berkesinambungan dengan alasan keterbatasan tenaga pelaksana dilapangan. Disamping itu belum adanya Kelompok Pendukung ASI (KP-ASI) di wilayah tersebut, memberikan kontribusi negatif terhadap cakupan pemberian ASI eksklusif.

Melihat potensi dan kondisi ibu hamil serta meyusui diwilayah kerja puskesmas Meurebo, sangat penting dibentuk suatu program yang bertujuan untuk meningkatkan pengetahuan ibu hamil dan meningkatkan kepatuhan ibu menyusui dalam dalam mewujudkan keluarga sadar ASI eksklusif melalui pendekatan peer group yaitu pembentukan Kelompok Pendukung ASI (KP-ASI). Anggota Kelompok Pendukung ASI dapat direkrut dari kader posyandu yang aktif dan berhasil memberikan ASI eksklusif pada bayinya. 


\section{METODE}

KP-ASI merupakan kelompok pemberdayaan pada masyarakat yang bertujuan untuk meningkatkan pemberian ASI eksklusif. Metode dalam pengabdian yaitu pembentukan KP- ASI sebagai role model untuk mewujudkan keluarga dasarsie (keluarga sadar ASI eksklusif).

Pengabdian ini melalui beberapa pendekatan, yaitu :

\section{Persiapan Pembentukan KP-ASI}

a. Surve lokasi pengabdian, advokasi dengan perangkat desa dan sosialisasi tujuan pembentukan KP-ASI

b. Pembentukan KP-ASI (Kelompok Pendukung ASI), dengan melakukan seleksi dari kader kesehatan, yaitu kader yang aktif dalam posyandu dan ibu - ibu yang berhasil memberikan ASI eksklusif pada bayinya.

c. Penyusunan Struktur organisasi dan prosedur kerja KP-ASI

2. Tahap Pelasanaan:

Edukasi terhadap KP-ASI (Kelompok Pendukung ASI), meliputi pelatihan, demo dan home visit.

3. Monitoring hasil edukasi pada KP-ASI meliputi kesiapan menjadi konselor ASI dan motivator pemberian ASI pada ibu hamil maupun ibu menyusui melalui kuisioner dan praktek langsung.

4. Pendampingan oleh KP-ASI terhadap ibu hamil dan ibu menyusui dalam meningkatkan pengetahuan dan ketrampilan menyusui.

5. Evaluasi pelaksanaan kegiatan pengabdian terhadap KP-ASI berdasarkan sikap sadar ASI dengan mengukur pengetahuan dan ketrampilan ibu terhadap pemberian ASI eksklusif.

\section{HASIL}

Pelaksanaan kegiatan pengabdian masyarakat ini terdiri dari tiga tahapan, yaitu

1. Tahap persiapan :

a) Survey awal lokasi pengabdian di Desa Paya Peunaga meliputi :

Pelaksanaan kegiatan diawali dengan pendekatan dengan perangkat desa untuk mensosialisasikan kegiatan yang akan dilakukan. Pendekatan dengan perangkat desa menunjukkan hasil yang baik karena kepala desa (Geuchik) memberikan respon positif terhadap pelaksanaan kegiatan "Pembentukan KP-ASI dalam mewujudkan KADARSIE".

b) Pemilihan KP-ASI dan sosialisasi pembentukan KP-ASI

Persiapan selanjutnya yang dilakukan oleh pelaksana pengabdian yaitu mendata kader kesehatan yang aktif dan ibu menyusui yang berhasil memberikan ASI eksklusif pada bayinya dalam kurun waktu 5 tahun. Berdasarkan pendataan di desa Paya Peunaga terdapat 7 kader kesehatan 
yang aktif dan 13 ibu yang berhasil memberikan ASI eksklusif pada bayinya. Data tersebut dijadikan acuan terhadap perekrutan KP-ASI. Selanjutnya dilakukan sosialisasi tujuan pembentukan KP - ASI dan kesepakatan bersama akan komitmen tugas dan tanggung jawab KP-ASI di tingkat desa. Hasil sosiasilasi meunjukkan komitmen yang tinggi dari 20 orang ibu dalam mendukung suksesnya pemberian ASI eksklusif, dan mereka dengan suka rela serta penuh kesadaran untuk menjadi anggota KP-ASI.

c). Terbentuknya KP-ASI
Berdasarkan kesepakatan bersama anggota KP - ASI di desa Paya terdiri tiga kelompok, yaitu KP-ASI Cut Nyak Dhien beranggotakan 7 orang, KP- ASI Cut Meutia beranggotakan 7 orang dan KP-ASI Laksamana Malahayati dengan anggota 6 orang.

2. Tahap Pelaksanaan

Pelaksanaan kegiatan pengabdian masyarakat ini meliputi beberapa kegiatan, diantaranya yaitu pelatihan, demo, dan home visit. Edukasi pada kelompok ASI ini dilakukan 4 kali pertemuan dalam sebulan, yang terangkum dalam table dibawah ini

\begin{tabular}{|c|c|c|c|c|}
\hline & \multicolumn{4}{|c|}{ Minggu I (Sosialisasi dan Pelatihan ) } \\
\hline Hari /tanggal & Materi & Metode & Capaian kegiatan & Alat Bantu \\
\hline $\begin{array}{l}\text { Minggu, } 4 \\
\text { November } \\
2018\end{array}$ & $\begin{array}{l}\text { I. Penjelasan } \\
\text { Peran KP ASI } \\
\text { di desa baik } \\
\text { sebagai } \\
\text { konselor } \\
\text { maupun } \\
\text { motivator } \\
\text { II. Penyuluhan } \\
\text { manfaat } \\
\text { pemberian } \\
\text { ASI eksklusif, } \\
\text { cara menyusui } \\
\text { yang benar } \\
\text { dan solusi } \\
\text { yang diberikan } \\
\text { II. Tata cara } \\
\text { mewujudkan } \\
\text { Keluarga } \\
\text { Sadar ASI } \\
\text { Eksklusif }\end{array}$ & $\begin{array}{l}\text { Ceramah } \\
\text { Tanya Jawab }\end{array}$ & $\begin{array}{l}\text { Motivasi dari KP } \\
\text {-ASI sangat baik } \\
\text { yang dibuktikan } \\
\text { jumlah kehadiran } \\
\text { dan interaktif } \\
\text { peserta KP - ASI } \\
\text { saat pelatihan }\end{array}$ & $\begin{array}{l}\text { Buku Saku ASI } \\
\text { Eksklusif Buku } \\
\text { KIA, Leaflet, dan } \\
\text { poster }\end{array}$ \\
\hline
\end{tabular}




\begin{tabular}{|c|c|c|c|c|}
\hline \multicolumn{5}{|c|}{ Minggu II (Demo Perawatan Payudara) } \\
\hline $\begin{array}{l}\text { Minggu, } 11 \\
\text { November } \\
2018\end{array}$ & $\begin{array}{l}\text { I. } \text { Manfaat } \\
\text { perawatan } \\
\text { payudara } \\
\text { saat hamil } \\
\text { dan } \\
\text { menyusui } \\
\text { II. Demo } \\
\text { Perawatan } \\
\text { payudara } \\
\text { dan cara } \\
\text { mengatasi } \\
\text { berbagai } \\
\text { masalah } \\
\text { payudara } \\
\text { saat } \\
\text { menyusui } \\
\text { terutama } \\
\text { pada ibu } \\
\text { primigravida } \\
\text { II. Praktek } \\
\text { langsung } \\
\text { perawatan } \\
\text { payudara } \\
\text { oleh anggota } \\
\text { KP - ASI } \\
\text { dengan } \\
\text { bantuan kit } \\
\text { konseling } \\
\end{array}$ & $\begin{array}{l}\text { Ceramah, } \begin{array}{r}\text { Tanya jawab, } \\
\text { Curah } \\
\text { ceramah, } \\
\text { praktek }\end{array} \\
\text { demonstrasi, }\end{array}$ & $\begin{array}{l}\text { Kehadiran } \\
\text { peserta } 100 \% \text {, } \\
\text { keseriusan saat } \\
\text { mendengarkan } \\
\text { penjelasan dan } \\
\text { kemampuan } \\
\text { dalam } \\
\text { mengulang } \\
\text { langkah - } \\
\text { langkah } \\
\text { perawatan } \\
\text { payudara seperti } \\
\text { yang sudah } \\
\text { dipraktikkan } \\
\text { oleh pemateri. }\end{array}$ & $\begin{array}{l}\text { Buku } \\
\text { Saku } \\
\text { Perawatan } \\
\text { Payudara, } \\
\text { Buku } \\
\text { KIA, } \\
\text { leaflet, } \\
\text { poster, } \\
\text { video } \\
\text { perawatan } \\
\text { payudara } \\
\text { dan kit } \\
\text { konseling } \\
\text { menyusui. }\end{array}$ \\
\hline \multicolumn{5}{|c|}{ Minggu ke III dan IV (Home Visit) } \\
\hline $\begin{array}{l}\text { Minggu } 18- \\
\text { Minggu } \\
\text { 25November } \\
2018\end{array}$ & \begin{tabular}{|l} 
1. Home visit \\
pada seluruh \\
KP- ASI di \\
desa Paya \\
Peunaga \\
2. Kegiatan \\
Home Visit \\
merupakan \\
kegiatan \\
edukasi \\
pendamping \\
an yang \\
dilakukan \\
khusus pada \\
tiap anggota \\
KP - ASI. \\
Materinya \\
sama pasa \\
saat \\
pelatihan
\end{tabular} & Tanya Jawab & $\begin{array}{l}\text { Motivasi yang } \\
\text { tinggi dari } \\
\text { peserta KP- } \\
\text { ASI } \\
\text { Kemampuan } \\
\text { peserta } \\
\text { pelatihan }\end{array}$ & $\begin{array}{l}\text { BukuSaku } \\
\text { Perawatan } \\
\text { Payudara, } \\
\text { Buku } \\
\text { KIA, } \\
\text { leaflet, } \\
\text { poster, } \\
\text { video } \\
\text { perawatan } \\
\text { payudara } \\
\text { dan kit } \\
\text { konseling } \\
\text { menyusui, } \\
\text { kuisioner }\end{array}$ \\
\hline
\end{tabular}




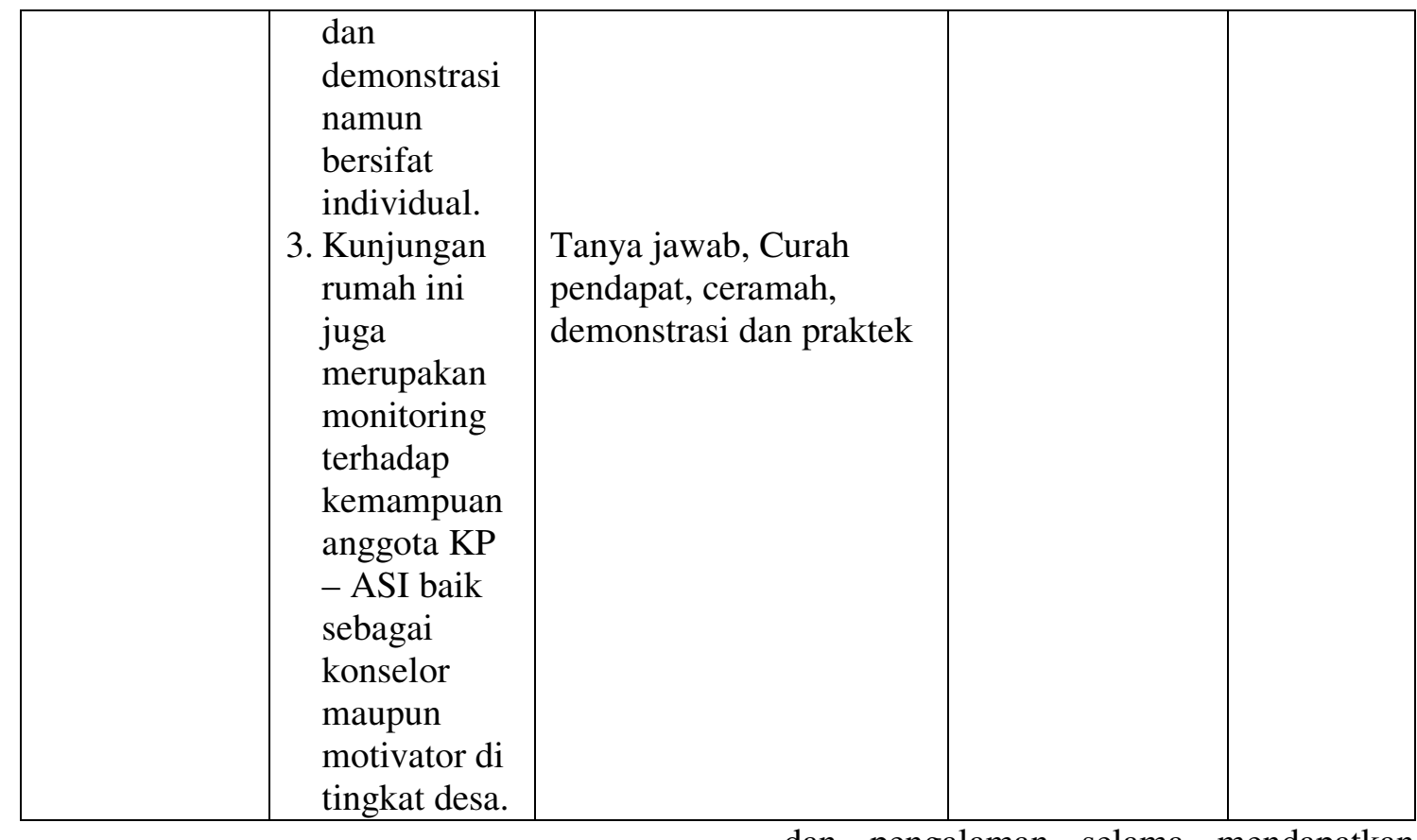

4. Tahap Monitoring

Kelompok Pendukung ASI melakukan edukasi pada Ibu hamil dan Ibu menyusui meliputi pengetahuan pemberian ASI Eksklusif, gizi dan perawatan payudara. Kelompok Pendukung ASI memberikan dan pengalaman selama mendapatkan pelatihan.

5. Tahap Evaluasi

Hasil evaluasi terhadap kegiatanedukasi KP - ASI ditunjukkan pada table berikut ini :

yang tepat sesuai dengan buku pedoman

Tabel 2. Distribusi Peserta Berdasarkan Pengetahuan Pada saat pre test dan post-test pada KP-ASI

\begin{tabular}{|l|c|c|c|c|c|c|}
\hline \multirow{2}{*}{ Kelompok Pendukung ASI } & \multicolumn{3}{|c|}{ Pre Test } & \multicolumn{4}{c|}{ Post Test } \\
\cline { 2 - 7 } & \multicolumn{3}{|c|}{ Cukup } & \multicolumn{2}{c|}{ Baik } & \multicolumn{2}{c|}{ Cukup } \\
\cline { 2 - 7 } & $\mathbf{N}$ & \% & N & \% & n & \% \\
\hline Cut Nyak Dhien & 7 & 100 & 5 & 71,4 & 2 & 28,5 \\
\hline Cut Mutia & 7 & 100 & 6 & 85,7 & 1 & 14,2 \\
\hline Laksamana Malahayati & 6 & 100 & 5 & 83.3 & 1 & 16.6 \\
\hline
\end{tabular}

Berdasarkan tabel di atas menunjukkan bahwa peserta mengalami peningkatan sebesar $85,7 \%$.

pengetahuan pada saat post tes dibandingkan nilai pada saat pre test. Pengetahuan peserta dikatakan baik jika dari 12 pertanyaan yang diberikan jawabannya benar $\geq 60 \%$. KP-ASI yang paling tinggi peningkatan pengetahuan 


\section{DOKUMENTASI KEGIATAN}
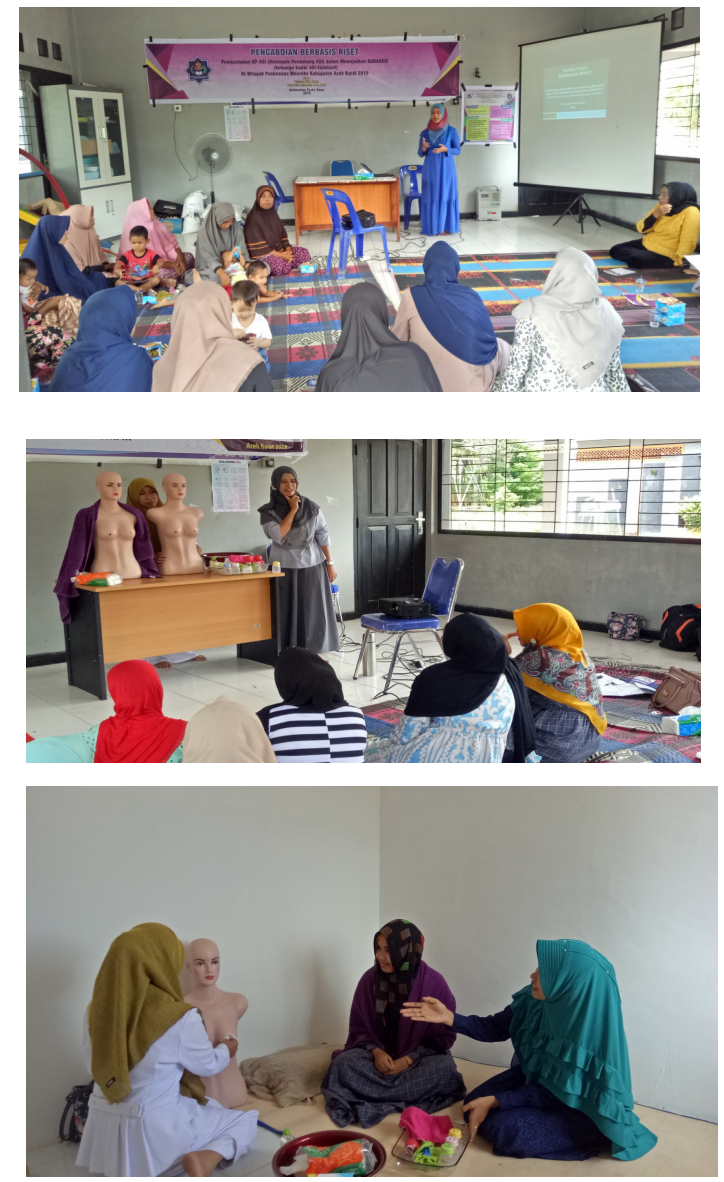

KESIMPULAN DAN SARAN

\section{Kesimpulan}

Kegiatan Pengabdian yang dilaksanakan selama 3 bulan dari tahap persiapan sampai dengan evaluasi dapat terlaksana dengan baik. Kader kesehatan yang tepilih sebagai anggota KP-ASI sangat antusias mengikuti kegiatan, sehingga memberikan kontribusi terhadap peningkatan pengetahuan.

\section{Saran}

Puskesmas dapat melibatkan KP-ASI sebagai sinergisistas keberhasilan program Pemberian ASI eksklusif di wilayah Meurebo.

\section{DAFTAR PUSTAKA}

Dinas Kesehatan Kabupaten Aceh Barat . 2013. Profil Kesehatan Kota Surakarta Tahun 2012

Kementrian Kesehatan Republik Indonesia. 2012. Peraturan Pemerintah Republik Indonesia Nomor 33 Tahun 2012 tentang Pemberian Air Susu Ibu Eksklusif

Kementrian Kesehatan RI, Direktorat jendral Bina Gizi dan Kesehatan Ibu dan Anak, Direktorat Bina Gizi. 2012. Petunjuk Pelaksanaan Surveilans Gizi.

Kristiyanasari, W. 2009.ASI, Menyusui dan SADARI. Nuha Medika. Yogyakarta

Keputusan Menteri Kesehatan Republik Indonesia. Nomor. 450/Menkes/SK/IV/2004

Proverawati, K. 2009. Buku Ajar Gizi untuk Kebidanan. Naha Medika, Yogyakarta

Poltekkes Kemenkes Aceh, 2017. Studi Monitoring dan Evaluasi Program Gizi Roesli, U. 2008. Inisiasi Menyusu Dini. Pustaka Bunda. Jakarta

Siswoyo, D. 2014. Tujuan dan Manfaat Pemberian ASI Eksklusif.

Sulistyaningsih, H. 2011. Gizi untuk Kesehatan Ibu dan Anak. Graha Ilmu Jakarta 